\title{
Partidos Políticos: Como Vem Se Dando Sua Territorialidade
}

\author{
Partidos Politicos: Cómo Viene Si Dando Su Territorialidad \\ Political Parties: How Their Territoriality Has Been Occurring
}

Matheus Pinto Furtado 1

Ronaldo Bernardino Colvero ${ }^{2}$

Danilo Pedro Jovino ${ }^{3}$

\begin{abstract}
Resumo
O presente trabalho se constitui em um estudo sobre o panorama da territorialidade dos partidos políticos no Brasil nos últimos anos, construindo-se a partir de questões conceituais. Objetiva-se compreender como vem se dando a territorialidade dos partidos políticos na busca de obtenção de votos entre os eleitores, se apresentando como uma ferramenta reflexiva sobre as ações das organizações partidárias no território. Além disto, visa-se analisar a relação de pouco vínculo entre os partidos e como esta liga-se com a territorialidade das organizações partidárias. Foi possível observar que partidos políticos vêm exercendo sua territorialidade na busca da conquista de votos fazendo uso de estratégias como o enfoque, por exemplo, na personalização, priorizando os atores e não as legendas. Tal ação vem levando, cada vez mais, a um enfraquecimento da relação de identificação do eleitorado com as siglas partidárias. A metodologia utilizada foi a qualitativa, utilizando o método bibliográfico tanto sobre território e a territorialidade quanto no que tange aos partidos políticos. Portanto, construiu-se o estudo visando a análise dos conceitos, além de evidenciar algumas das estratégias dos partidos diante do território para a conquista do poder.
\end{abstract}

Palavras-Chave: Ciência Política; Partidos Políticos; Território; Territorialidade.

\section{Resumen}

El presente trabajo se constituye en un estudio sobre el panorama de la territorialidad de los partidos políticos en Brasil en los últimos años, construyéndose a partir de cuestiones conceptuales. Se pretende comprender cómo se viene dando la territorialidad de los partidos políticos en la búsqueda de obtención de votos entre los electores, presentándose como una herramienta reflexiva sobre las acciones de las organizaciones partidistas en el territorio. Además, se pretende analizar la relación de poco vínculo entre los partidos y cómo ésta se vincula con la territorialidad de las organizaciones partidistas. Es posible observar que partidos políticos vienen ejerciendo su territorialidad en la búsqueda de la conquista de votos haciendo uso de estrategias como el enfoque, por ejemplo, en la personalización, priorizando a los actores y no a las leyendas. Tal acción viene llevando, cada vez más, a un debilitamiento de la relación de identificación del electorado con las siglas partidistas. La metodología utilizada fue la cualitativa, utilizando el método bibliográfico tanto sobre territorio y la territorialidad como en lo que se refiere a los partidos políticos. Por lo tanto, se construyó el estudio buscando el análisis de los conceptos, además de evidenciar algunas de las estrategias de los partidos frente al territorio para la conquista del poder.

\footnotetext{
${ }^{1}$ Graduando em Ciências Humanas - Licenciatura; Universidade Federal do Pampa - UNIPAMPA; São Borja, Rio Grande do Sul, Brasil; matheusftd@gmail.com.

${ }^{2}$ Professor Doutor no curso de Ciências Sociais - Ciência Política; Universidade Federal do Pampa -

UNIPAMPA; São Borja, Rio Grande do Sul, Brasil; rbcolvero@gmail.com.

${ }^{3}$ Mestrando em Políticas Públicas; Universidade Federal do Pampa - UNIPAMPA; São Borja, Rio Grande do Sul, Brasil; danilopedro_gda@hotmail.com.
} 
Palabras claves: Ciencia Política; Partidos Políticos; Territorio; Territorialidad.

\begin{abstract}
The present work constitutes a study about the panorama of the territoriality of political parties in Brazil in recent years, building on conceptual issues. The objective is to understand how the territoriality of political parties has been achieved in the search for votes among voters, presenting itself as a reflective tool on the actions of party organizations in the territory. In addition, it aims to analyze the relationship of little link between the parties and how this links with the territoriality of party organizations. It was possible to observe that political parties have been exerting their territoriality in the search for the conquest of votes making use of strategies such as the focus, for example, on personalization, giving priority to actors rather than parties. Such action has led, increasingly, to a weakening of the relation of identification of the electorate with the party acronyms. The methodology used was qualitative, using the bibliographic method both on territory and territoriality as well as on political parties. Therefore, the study was constructed aiming at the analysis of the concepts, besides evidencing some of the strategies of the parties before the territory for the conquest of the power.
\end{abstract}

Keywords: Political Science; Political Parties; Territory; Territoriality.

\title{
1. Introdução
}

Quando fala-se em território, logo pensa-se apenas em extensões de terra delimitadas, como municípios, estados ou países, e isto representa grande parte da perspectiva do senso comum. Contudo, antes de partir ao conceito deste, se faz necessária uma contextualização, mesmo que breve, sobre o espaço, partindo do pressuposto de que este é anterior ao território (RAFFESTIN, 1993).

O espaço, segundo Leffebvre, se dá como "a materialização da existência humana" (1991, p. 102 apud FERNANDES, 2013, p. 193), e é preciso que se pense sobre este não de maneira a caracterizá-lo como fragmento, mas como totalidade. Nesta perspectiva, Milton Santos define o espaço como "conjunto de sistemas de objetos e sistemas de ação, que formam o espaço de modo, indissociável, solidário e contraditório" (SANTOS, 1996, p. 51 apud FERNANDES, 2013, p. 193). Nesta definição estão inseridas a natureza e a sociedade. Por sistemas de objetos são entendidos os objetos naturais - elementos da natureza - e os objetos sociais ou objetos produzidos por meio das relações sociais, que modificam e transformam a natureza (FERNANDES, 2013).

Para autores como Raffestin (1993), no que se trata, agora, sobre território, não há somente uma demarcação de espaço, mas também uma caracterização do território como sendo a cena do poder e o lugar onde se dão todas relações. Neste raciocínio, Fernandes destaca que o território "não é uma técnica, muito menos uma noção fechada, acabada, determinada. Não pode ser naturalizado, instrumentalizado, aparelhado. O sentido do uso do conceito de território é o político" (2013, p. 208). Através disto, é possível pensar em um conceito dentro da Geografia que relaciona as questões de controle e também de território: o de territorialidade. 
Na visão de Soja (apud SANTOS, 2009), a territorialidade é um fenômeno de caráter comportamental, que está associado à organização do espaço ou de territórios que são demarcados de forma latente, considerados diferenciado e exclusivos, pelo menos de maneira parcial, pelos sujeitos inseridos em tais espaços ou por pessoas que assim os veem. Em suma, num determinado território há grupos de indivíduos que enxergam este espaço com exclusividade, exercendo, através da ação sobre tal, um controle ou poder. Para Sack, a territorialidade é um "comportamento humano espacial, se dá como uma expressão de poder que não é nem agressiva e, tampouco, instintiva. Se constitui, apenas, em uma estratégia humana para afetar, influenciar e controlar o uso social do espaço" (1986, apud SANTOS, 2009, p. 3).

Em ligação com o conceito de territorialidade, é possível pensar, como grupo de indivíduos que agem sobre o território exercendo influência, os partidos políticos. Tendo estes como objetivo principal a vitória em processos eleitorais (PRAÇA; DINIZ, 2007), uma vez no poder, exercem controle sobre determinado território, como em um dos estados brasileiros, por exemplo. E, além disto, buscam uma perpetuação, no caso de partidos que já estejam no poder - ou a conquista de tal através das campanhas eleitorais -, agindo sobre o contexto territorial em que estão inseridos, tomando este espaço como trunfo, como colocam Quadros e Cruz (2014).

Os partidos, segundo Quadros e Cruz (2014), contraditoriamente contribuem para reforçar a ausência de preferência partidária por parte dos eleitores, pois usam da personalização da política, destacando nomes e não os partidos e a formação de coligações, o que contribui para a perca de percepção ou identificação dos eleitores em relação aos partidos. É possível observar que as organizações partidárias não mais possuem vínculos fortes com os eleitores, que garantiam às mesmas a convicção de votos de determinadas camadas da sociedade. O que se percebe são novos tipos de estratégia adotados pelos partidos políticos durante as disputas eleitorais, novas ações sobre o território que visam o controle sobre este.

O presente trabalho objetiva compreender como vem se dando a territorialidade dos partidos políticos na busca de obtenção de votos entre os eleitores, se apresentando como uma ferramenta reflexiva sobre as ações das organizações partidárias no território. Além disto, visa analisar a cultura política brasileira de pouco vínculo entre os partidos e o eleitorado, e como esta liga-se com a territorialidade das organizações partidárias. $\mathrm{O}$ trabalho se torna relevante em função de analisar como os partidos políticos vem exercendo sua territorialidade na busca da conquista de votos, fazendo uso de estratégias como o enfoque, por exemplo, na personalização, priorizando os atores e não as legendas. Tal ação leva, cada vez mais, a um 
enfraquecimento da relação de identificação do eleitorado com as siglas partidárias. Usando de uma metodologia qualitativa, houve a revisão da literatura tanto sobre território e a territorialidade, quanto no que tange aos partidos políticos. Assim, construiu-se o estudo visando a análise dos conceitos, além de evidenciar as estratégias dos partidos diante do território para a conquista do poder, bem como para a continuação do exercício deste.

\section{Conceituando: Território}

Quando se fala em territorialidade, relaciona-se esta nomenclatura a questões geográficas, ou, mais precisamente, ao território. Contudo, é necessário que se entenda, antes, o conceito deste segundo para que haja a compreensão do primeiro. E dentre os conceitos de território existentes na Geografia, serão usados, aqui, definições de autores como Claude Raffestin, entre outros.

Em uma abordagem que mistura o subjetivo com o objetivo sobre o território, Haesbaert e Limonad colocam que "sem dúvida o homem nasce com o território, e vice-versa, o território nasce com a civilização" (2007, p. 42). E os homens, ao se conscientizarem sobre o espaço em que se inserem, o que, segundo os autores, é uma visão mais subjetiva, e ao se apropriarem, cercarem este espaço - visão mais objetiva -, passam a construir e, de certo modo, a ser construídos pelo território (HAESBAERT; LIMONAD, 2007). Isto caracteriza o território como uma construção, feita pelo homem e também influenciadora deste.

Segundo Raffestin, o território caracteriza-se como "o espaço político por excelência, como a cena do poder e o lugar de todas as relações" (1993, p. 60). De tal ponto de vista, o território "é essencialmente um instrumento de exercício de poder, ou seja, é uma espécie de trunfo a ser dominado e controlado pelos atores sintagmáticos (atores que realizam ações sobre o território em qualquer nível)" (QUADROS; CRUZ, 2014, p. 1092). Na mesma perspectiva em relação ao território como um cenário de poder, Moraes compreende-o como:

[...] um espaço de exercício de um poder, o qual no mundo moderno se apresenta como um poder basicamente centralizado no Estado. Trata-se, portanto, da área de manifestação de uma soberania estatal, delimitada pela jurisdição de uma dada legislação e de uma autoridade. O território é, assim, qualificado pelo domínio político de uma porção da superfície terrestre (MORAES, 2003, p. 1 apud RUCKERT, 2005, p. 83).

Seguindo um pensamento semelhante ao de Raffestin, Ratzel define o território como "um espaço qualificado pelo domínio de um grupo humano, sendo definido pelo controle político de um âmbito espacial" (apud MORAES, 2000, p. 19). A partir deste pensamento, é 
possível observar que poder e território possuem estreita ligação. Isto se dá pois, além da questão do controle através do espaço, neste contexto há, também, a "capacidade de controlar, de influenciar a ação de outras pessoas" (CLAVAL, 1979, p. 11 apud QUADROS; CRUZ, 2014, p. 1093).

Tendo em mente este raciocínio sobre a influência não somente sobre o espaço, mas também sobre os indivíduos, uma ligação entre território e partidos políticos surge. Contudo, as organizações partidárias objetivam o poder não somente sobre o território, mas, principalmente sobre a população que neste está inserida (QUADROS; CRUZ, 2014). Sobre isto, é possível refletir sobre a colocação de Raffestin (1993, p. 58), que diz que "o poder visa o controle e a dominação sobre os homens e as coisas. [...] a população em primeiro lugar [...] porque ela está na origem de todo poder".

Assim, as informações sobre a população de determinado território constituem um elemento fundamental para que os partidos políticos exerçam seu poder. Segundo Castro, é a "força de propagação de uma vontade a outras, graças à mediação de uma vontade comum, ou seja, sob o fundo dessa vontade comum, o poder pode dispor de outras vontades e orientá-las e informá-las segundo seus [...] interesses" (2011, p. 101). Isto relaciona-se com o conhecimento do território e da população inserida neste para que os partidos possam exercer influência não somente no primeiro, mas, principalmente, sobre o segundo. Mas para que isso se torne mais claro, é necessário abordar o que são, de fato, partidos políticos. Além disto, os próximos parágrafos deste estudo também abordarão a conceituação de territorialidade para que seja possível perceber a relação entre esta e a ação das organizações partidárias no território.

\section{Partidos Políticos e Territorialidade}

Atualmente, é possível observar nas diferentes mídias a presença do tema partidos políticos. Se fala e também discute-se sobre estes. Há a escolha por um ou outro partido de acordo com a ideologia de cada indivíduo, e, muitas vezes, há conflitos surgidos a partir de posições partidárias divergentes.

Contudo, é importante que, em meio ao emaranhado de informações existentes, se levante uma questão: afinal, o que são partidos políticos? Tem-se a ideia de partido político como sendo um grupo de indivíduos que, teoricamente, representa os interesses de determinadas parcelas da sociedade, dando-as voz. Contudo, é importante que, em meio ao senso comum, se vá ao encontro da cientificidade. Segundo os autores Praça e Diniz, partidos políticos são: 
[...] organizações criadas por líderes para disputar eleições [...] são frutos dos anseios de partes específicas da sociedade, unidas em torno de interesses comuns. Partidos políticos têm um objetivo principal: vencer eleições [...] são canais de participação política usados pela sociedade civil para tornar possível a realização de demandas populares (PRAÇA; DINIZ, 2007, p. 5).

Portanto, a partir da perspectiva de Praça e Diniz, os partidos políticos nascem a partir da iniciativa de figuras de liderança dentro da sociedade, visando atender anseios e demandas de certos grupos sociais que, através destas organizações, se fazem representados. E é possível notar, quando se trata do objetivo principal, a questão da vitória nos processos eleitorais, o que leva a organização à conquista do poder e do controle em determinado espaço territorial. D’Araújo ressalta, ainda, que a organização partidária, em um apanhado geral, é “elemento essencial ao progresso social. A representação regular dos interesses sociais leva aos regimes estáveis, graças ao confronto normal e ordenado" (1992, p. 9).

A definição dos autores se dá de forma delimitada e em um contexto contemporâneo, mas também há, sobre o mesmo tema, outras definições que merecem abordagem. Em se tratando de definições clássicas, é possível citar a definição de partidos políticos de Max Weber, de caráter abrangente, e de Maurice Duverger, pouco mais delimitada. Segundo Weber, o partido é toda associação voltada para a disputa e o exercício do poder, e, deste modo:

[...] sua característica fundamental seria influenciar ações sociais de qualquer conteúdo. De acordo com uma definição tão abrangente, partidos podem-se formar para disputar o poder num Estado, mas também num clube, numa associação ou num sindicato. Em todos esses grupos, a disputa coletiva pelo poder obedeceria à mesma lógica (WEBER, 1991 apud ARAÚJO, 2004, p. 3-4).

Para Duverger, a linguagem cotidiana restringe o uso da palavra partido aos grupos organizados para a disputa e exercício do poder no âmbito de uma organização estatal. Contudo, para o autor, esta restrição ainda é insuficiente. Com tal definição, a palavra “continua a englobar facções de todo tipo [...]" (DUVERGER, 1970 apud ARAÚJO, 2004, p. 4). Neste contexto, é possível partir das visões de Weber e Duverger e delimitar o olhar sobre a definição de partido político segundo o conceito de Praça e Diniz.

O poder e o controle adquiridos pelos partidos através da vitória nos pleitos relacionam-se com a ação de tais organizações em determinado território, e esta relação vai de encontro com a questão da territorialidade defendida por Soja. Segundo o autor, no âmbito da conotação política da organização do espaço pelo homem, a territorialidade pode ser vista 
como um fenômeno de cunho comportamental associado à organização do espaço em esferas de influência, ou de territórios demarcados de forma clara, considerados distintos, exclusivos, ao menos parcialmente, por seus ocupantes ou por outros agentes que assim os definam (SOJA, 1971 apud SANTOS, 2009).

Sobre a territorialidade, é possível uma breve exemplificação: em uma escola determinado território -, é possível encontrar grupos de jovens reunidos antes da aula. Estes estão sempre no mesmo espaço e no mesmo horário. Contudo, se for observado o mesmo espaço em uma hora diferente do dia, haverá outro grupo com outras características naquele espaço onde, antes, estavam os outros indivíduos. Cada um dos grupos caracteriza-se de maneira a diferenciar-se dos demais, tornando claro que um objetivo comum os une. Em conclusão, um tipo de "poder/controle" é exercido sobre certo espaço em determinadas horas do dia ou da noite através da ação dos grupos no território.

Raffestin aponta que, além de uma relação homem-território, existe a relação social entre os indivíduos. E, sendo assim, a territorialidade seria, também, "um conjunto de relações que se originam num sistema tridimensional sociedade-espaço-tempo em via de atingir a maior autonomia possível, compatível com os recursos do sistema" (RAFFESTIN, 1993, p. 160). Ainda na perspectiva de relação entre os indivíduos dentro de um território, de acordo com Sack, é possível adotar, ainda que provisoriamente, o conceito de territorialidade como "a tentativa por indivíduos ou grupos para afetar, influenciar ou controlar pessoas, fenômenos e relações, pela delimitação e estabelecimento de controle sobre uma área geográfica" (1986, p. 19-20 apud RUCKERT, 2005, p. 88).

Os partidos políticos, como já visto, caracterizam-se como organizações de representação que objetivam o poder e agem em determinado território; e a territorialidade se dá através da ação/controle de determinado grupo em um certo contexto social, espaço e tempo. Neste ponto do estudo, é possível perceber uma relação. Nos próximos parágrafos, partindo de uma análise da cultura política brasileira, relacionada com o exercício da cidadania através dos direitos políticos, será visto como vem se dando a territorialidade das organizações partidárias.

\section{Como Vem Se Dando A Territorialidade Dos Partidos Políticos}

Com o fim do regime militar, em 1985, uma das primeiras medidas do governo da Aliança Democrática foi aprovar no Congresso a Emenda Constitucional de $n^{\circ} 25$, de 15 de maio de 1985. Esta, dentre outras disposições, restabeleceu as eleições presidenciais diretas e retirou da Constituição o dispositivo referente à fidelidade partidária, além de autorizar a livre 
criação de novos partidos políticos e a reorganização de todas as siglas que tivessem tido os seus registros indeferidos, cancelados ou cassados durante a ditadura civil-militar (SCHMITT, 2005).

A Emenda Constitucional de $\mathrm{n}^{\circ} 26$, de 27 de novembro de 1985 determinou que o Congresso Nacional, que seria eleito em 1986, estaria dotado de atribuições constituintes, ficando encarregado de elaborar a nova Constituição brasileira. Ainda no mesmo ano, em 30 de dezembro de 1985, foi aprovada a Lei nº7.454, que alterou vários dispositivos do Código Eleitoral que vigorava desde 1965. A nova configuração permitiu, por exemplo, que todos os partidos, tanto os com registro provisório como os em formação, pudessem participar das eleições para a Assembleia Nacional Constituinte - ANC (SCHMITT, 2005).

A nova Constituição brasileira, promulgada em 1988, e caracterizada como sendo "a mais liberal e democrática que o país já teve, merecendo por isso o nome de Constituição Cidadã" trouxe o estabelecimento de direitos políticos dotados de "amplitude nunca antes atingida" (CARVALHO, 2012, p. 199). Segundo Carvalho (2012), tornou-se comum desmembrar a cidadania em três direitos, dentre eles os políticos, além dos direitos civis e sociais. O cidadão pleno seria aquele titular dos três. Os que não beneficiam-se de apenas alguns dos três seriam cidadãos incompletos, e os que não se beneficiam de nenhuma maneira são caracterizados como não cidadãos.

A partir disto, o autor esclarece os conceitos. Direitos civis são os direitos fundamentais à vida, à liberdade, à propriedade, à igualdade perante a lei, e os direitos sociais "garantem a participação na riqueza coletiva. Eles incluem o direito à educação, ao trabalho, ao salário justo, à saúde, à aposentadoria" (CARVALHO, 2012, p. 10). Sobre os direitos políticos, Carvalho coloca que estes referem-se:

[...] à participação do cidadão no governo da sociedade. Seu exercício é limitado a parcela da população e consiste na capacidade de fazer demonstrações políticas, de organizar partidos, de votar, de ser votado. Em geral, quando se fala de direitos políticos, é do direito de voto que se está falando (CARVALHO, 2012, p. 9).

A Constituição de 1988, segundo Carvalho (2012) eliminou o que era o grande problema relacionado à universalidade do voto, tornando-o facultativo aos analfabetos e dando fim a uma discriminação injustificável. Além disto, o critério de idade para aquisição do direito ao voto foi reduzido de 18 para 16 anos, idade mínima para a aquisição de capacidade civil relativa. Lembrando que o voto a partir de 16 anos é facultativo, passando a ser obrigatório apenas aos 18 anos. 
Conforme lembra Carvalho (2012), a única restrição que permaneceu, advinda da Constituição anterior, foi a proibição de voto aos conscritos, ou seja, aqueles que foram convocados a prestar serviço militar obrigatório. O autor ressalta que, "embora também injustificada, a proibição atinge parcela pequena da população e apenas durante período curto de vida" (2012, p. 200-201). A proibição do voto também se estendeu aos estrangeiros. É possível observar, a partir das disposições relacionadas aos direitos políticos na Carta Magna de 1988, uma inserção de maior número de indivíduos participando, de maneira efetiva, do cenário político e exercendo sua cidadania através do voto.

No que tange aos partidos políticos, a Constituição também trouxe mudanças. Uma vez que, durante o regime militar, havia obstáculos relacionados à organização e funcionamento dos partidos, a legislação vigente possui caráter pouco restritivo. O Tribunal Superior Eleitoral passou a aceitar registro provisório de partidos apenas 30 assinaturas, e este permite que o partido concorra nas eleições e dá acesso à televisão para a campanha (CARVALHO, 2012). Dentro do caráter liberal da Carta Magna de 1988, Carvalho coloca a questão da liberdade dada pela legislação:

Foi também extinta a exigência de fidelidade partidária, isto é, o deputado ou senador não é mais obrigado a permanecer no partido sob pena de perder o mandato. Senadores, deputados, vereadores, bem como governadores e prefeitos, trocam impunemente de partido [...] De um excesso de restrição passou-se a grande liberdade (CARVALHO, 2012, p. 201).

Com este contexto em mente, pode-se partir a uma abordagem sobre a questão do desinteresse político por parte dos cidadãos nos últimos anos, fator relacionado ao exercício da cidadania e à cultura política. Esta última é definida como "[...] a distribuição particular de padrões de orientação política com respeito a objetos políticos entre os membros da nação" (ALMOND e VERBA, 1989, p. 13 apud BORBA, 2005, p. 149). É importante, ainda, lembrar que a população, como coloca Raffestin (1993), está na origem de todo poder, e é através desta que os partidos políticos obtém os votos que levam às vitórias nos processos eleitorais, ou seja, ao poder.

$\mathrm{Na}$ sociedade brasileira, nos últimos anos, é possível enxergar certo desinteresse em relação à política por boa parte da população. Esta opta por dar prioridade a seus interesses de caráter particular, deixando a tarefa de fazer e pensar política aos técnicos e políticos profissionais. O senso comum, habitualmente, enxerga a política como um conjunto de decisões governamentais que são feitas de cima para baixo, devendo esta ser cumprida acima de qualquer outro tipo de interesse. Deste modo, os cidadãos começam a se decepcionar cada 
vez mais com os políticos e com a política em si. E sobre tal contexto, Ridenti expõe da seguinte maneira:

Ao invés de perceber-se como sujeito político, que pode atuar para a transformação social, o cidadão em potencial prefere fechar-se em seu mundo privado, desencantado com a política. Esse aparente desinteresse político no fundo indica distanciamento crítico da política governamental, mas acaba paradoxalmente por reforça-la: quem cala consente. Todos sofrem as consequências dos atos políticos do governo, que tendem a perpetuar-se caso não surja uma oposição organizada e combativa contra eles (RIDENTI, 1992, p. 51).

Tal espécie de conformismo, ou omissão de tomada de posição política, acaba transformando-se em uma forma de posicionamento, que tem a ordem política como algo dado, irreversível. Segundo Ridenti (1992), tal desprezo pela política que é praticada serve de ferramenta para a continuidade desta, pois acaba não negando-a. E todo este contexto se mostra ligado à falta de representação e articulação por parte dos partidos em relação aos interesses da população no sistema político - o que, teoricamente, deveria ocorrer. Sobre o vínculo representativo entre partidos políticos e população, Meneguello (1998) aponta que as novas condições do relacionamento entre o eleitor e o político, marcado pela ação dominante dos meios de comunicação de massa, priorizam a personalização e a imagem ao invés da mediação partidária. Nesse contexto, o processo de formação das preferências políticas passa a buscar parâmetros em um amplo campo de informações, através do qual dá-se a percepção das questões e temas públicos, e não mais a partir de linhas de opinião estruturadas sobre clivagens ou interesses específicos organizados, estabelecidos tradicionalmente pelos partidos políticos (MENEGUELLO, 1998).

De acordo com Silveira (1998 apud AUGUSTO; SENE, 2013) há, no Brasil, uma alienação eleitoral, e esta liga-se com um fator relevante para a discussão sobre a identificação partidária: a alienação em função da desinformação. Segundo o autor, o eleitor politicamente desinformado, sem o conhecimento em relação aos problemas de cunho político e aos "projetos, propostas, partidos e candidatos concorrentes nos processos eleitorais, se autoexclui do jogo político porque não se vê reunindo mínimas condições para participar”. (SILVEIRA, 1998, p. 121 apud AUGUSTO; SENE, 2013, p. 86). Segundo Augusto e Sene (2013), através de uma perspectiva da Geografia Eleitoral é possível observar diferentes (re) configurações do espaço geográfico, percebendo os elementos que possuem influência no comportamento eleitoral, como as características sociais do eleitorado, tais como renda e escolaridade, que por sua vez podem influenciar no voto deste eleitor. 
Em tal contexto, Kinzo coloca que "o pouco vinculo partidário-eleitoral também ocorre em função do pouco conhecimento, entre os eleitores do sistema partidário brasileiro [...]" (2005 apud REBELLO, 2012, p. 51-52). Com este distanciamento entre os partidos e a população em função da falta de organização e representação partidária, e também da falta de conhecimento em relação ao sistema partidário por parte do eleitorado, as organizações enxergam a necessidade de traçar novas estratégias de conquista de votos.

Os partidos, segundo Quadros e Cruz (2014), contraditoriamente contribuem para reforçar a ausência de preferência partidária por parte dos eleitores, pois vem usando da personalização da política, destacando nomes e não os partidos e a formação de coligações, o que contribui para a perca de percepção ou identificação dos eleitores em relação aos partidos. É possível, a este ponto, constatar que as organizações partidárias não mais possuem vínculos fortes com os eleitores, que garantiam às mesmas a convicção de votos de determinadas camadas da sociedade. $\mathrm{O}$ que se percebe são estes novos tipos de estratégia adotados pelos partidos políticos durante as disputas eleitorais, estas novas ações que visam o controle do território. Isto vai de encontro com a questão dos partidos e sua territorialidade, ou seja, sua ação dentro de determinado espaço, visando a conquista ou a continuidade do exercício do poder.

Com os partidos tendo que utilizar de novas alternativas para a conquista do controle - através do voto -, ou a manutenção deste, a ação destes dentro do território também acaba por se modificar. A população não possui a mesma identificação com os partidos, e sim com os atores, havendo um movimento de personalização, e também a ligação entre figuras passadas da política e os candidatos atuais, o que se torna fator influenciador na decisão dos eleitores. Sobre isto, Rebello aponta que "de um modo geral a avaliação retrospectiva de um governo é muito importante para que um candidato governista venha obter fracasso ou sucesso" (2012, p. 49).

Com uma nova dinâmica dos partidos para manter ou conquistar o controle dentro do território, observar-se a relação entre o território e a ação dos partidos políticos de forma próxima. Em função da não proximidade com os eleitores, os partidos mudam sua ação dentro do contexto territorial para a obtenção de resultados satisfatórios nos pleitos. E uma destas ações está relacionada, segundo Maiwaring, à formação de "coligações esdrúxulas, inconsistentes e diferenciadas nos diversos estados do Brasil para obtenção de bons resultados” (2003 apud SOUZA; CAVALCANTE, 2012, p. 3). Isto, na percepção do autor, dificulta a criação de laços de lealdade entre os eleitores e as siglas partidárias. 
Como pode-se perceber, os partidos vêm exercendo sua territorialidade - agindo sobre o território no intuito de conquista/perpetuação do poder - usando de diversas ferramentas, estas adequadas ao contexto político do território onde cada organização está inserida. De alianças inconsistentes e personalização da política até ligação com governantes anteriores "bem sucedidos", a ação dos partidos sobre o espaço se molda com o intuito de vencer os processos eleitorais. E neste ponto do estudo, a relação entre partidos políticos e territorialidade se torna evidente, sendo que esta segunda é a ação do primeiro - grupo de indivíduos - dentro de determinado espaço, sempre voltado ao que toda organização partidária almeja ou tenta manter: o poder. Portanto, as iniciativas, a ação dos partidos políticos no território, ou seja, a sua territorialidade vem a influenciar na conquista/perpetuação ou não do poder destes em relação ao contexto territorial onde estão inseridos.

É possível considerar, então, novos tipos de estratégia adotados pelos partidos políticos durante as disputas eleitorais como ferramentas para obtenção de votos, visando exercer o controle sobre o território. Com iniciativas visando adquirir votos - por vezes contraditórias -, ligadas tanto à não identificação da população com as legendas quanto com o desconhecimento desta em relação ao sistema partidário, observou-se que a ação das organizações no território não contribui na identificação dos eleitores com os partidos. Ao invés do fortalecimento da representatividade partidária, o que se percebe é o enfraquecimento da relação entre as legendas e o eleitorado, causando um distanciamento cada vez maior entre as parcelas sociais que deveriam se ver representadas e os partidos que, teoricamente, as representariam.

\section{Referências}

AUGUSTO, Daniel Cirilo; SENE, Michael Wellington. Geografia eleitoral e a decisão do voto: estudo a partir da identificação partidária. Revista Geonorte, Edição Especial 3, V.7, N.1, p. 81-97, 2013. Disponível em: <http://www.periodicos.ufam.edu.br/revistageonorte/article/viewFile/1155/1045>. Acesso em: 07 jun. 2017.

ARAÚJO, Caetano Ernesto P. Partidos políticos: há futuro para o monopólio da representação? Brasília: Consultoria Legislativa do Senado Federal, 2004. Disponível em: $<$ https://www12.senado.leg.br/publicacoes/estudos-legislativos/tipos-de-estudos/textos-paradiscussao/td-1-partidos-politicos-ha-futuro-para-o-monopolio-da-representacao>. Acesso em: 07 jun. 2017.

BORBA, Julian. Cultura política, ideologia e comportamento eleitoral: alguns apontamentos teóricos sobre o caso brasileiro. Opinião Pública. Campinas, vol. XI, no 1 , Março, 2005, p. 147-168. Disponível em: 〈http://www.scielo.br/pdf/op/v11n1/23698.pdf>. Acesso em: 07 jun. 2017. 
CARVALHO. José Murilo de. Cidadania no Brasil: o longo caminho. 15 ed. Rio de Janeiro: Civilização Brasileira, 2012.

CASTRO, Iná Elias de. Geografia e política: território, escalas de ação e instituições. Rio de Janeiro: Bertrand Brasil, 2011.

D’ARAUJO, Maria Celina. Sindicatos, carisma e poder: o PTB de 1945 a 1965 . Rio de Janeiro: Editora da Fundação Getúlio Vargas, 1996.

FERNANDES, Bernardo Mançano. Construindo um estilo de pensamento na questão agrária: o debate paradigmático e o conhecimento geográfico. Tese (livre-docência) Universidade Estadual Paulista, Faculdade de Ciências e Tecnologia. Presidente Prudente, $2013 . \quad$ Disponível em: <https://repositorio.unesp.br/bitstream/handle/11449/106708/fernandes_bm_ld_prud.pdf?se quence $=1>$. Acesso em: 07 jun. 2017.

HAESBAERT, Rogério; LIMONAD, Ester. O território em tempos de globalização. Etc..., espaço, tempo e crítica, Revista Eletrônica Científica de Ciências Humanas e Sociais e outras coisas. N. 2, V. 1, p. 39-52, 2007. Disponível em: <http://www.uff.br/etc/UPLOADs/etc\%202007_2_4.pdf>. Acesso em: 07 jun. 2017.

MENEGUELLO, Rachel. Partidos e governos no Brasil contemporâneo (1985-1997). São Paulo: Paz e Terra, 1998.

MORAES, A. C. Bases da formação territorial do Brasil: o território colonial brasileiro no longo século XVI. São Paulo: Hucitec, 2000.

PRAÇA, Sergio; DINIZ, Simone. Partidos políticos: funcionam? São Paulo: Paulus, 2007.

QUADROS, Camila Barata; CRUZ, Sâmia Karollyne Moura da. Um estudo da territorialidade dos partidos políticos a partir dos municípios de Belém no período de 20002012. Anais do I Congresso Brasileiro de Geografia Política, Geopolítica e Gestão de Território. Rio de Janeiro, p. 1091-1104, 2014. Disponível em: $<$ http://www.editoraletra1.com/anais-congeo/arquivos/978-85-63800-17-6-p10911104.pdf>. Acesso em: 07 jun. 2017.

RAFFESTIN, Claude. Por uma Geografia do poder. São Paulo: Ática, 1993.

REBELLO, Maurício. Afinal, quem é governo? Percepção eleitoral sobre o sistema partidário brasileiro nas eleições de 2000 a 2006. In: SANTOS, André Marenco dos; et al. Peças e engrenagens dos jogos políticos do Brasil. São Leopoldo: Oikos; São Luís: EDUFMA, 2012.

RIDENTI, Marcelo. Política pra quê? Atuação partidária no Brasil contemporâneo. São Paulo: Atual, 1992.

RUCKERT, Aldomar A. Reforma do Estado, Reestruturações territoriais, desenvolvimento e novas territorialidades. GEOUSP - Espaço e Tempo, São Paulo, N. 17, p. 79-94, 2005. Disponível em: <http://www.geografia.fflch.usp.br/publicacoes/Geousp/Geousp17/Artigo5_Aldomar.pdf>. Acesso em: 07 jun. 2017.

SANTOS, Carlos. Território e Territorialidade. Revista Zona de Impacto. V. 13, 2009. Disponível 
<http://www.albertolinscaldas.unir.br/TERRITÓRIO\%20E\%20TERRITORIALIDADE_vol ume13.html>. Acesso em: 07 jun. 2017.

SCHMITT, Rogério. Partidos Políticos no Brasil: (1945-2000). 3 ed. Rio de Janeiro: Jorge Zahar Editora, 2005.

SOUZA; Carlos Augusto; CAVALCANTE, Maria Jeane da Silva. Padrões geográficos das coligações eleitorais no Brasil: uma análise pela perspectiva ideológica dos partidos políticos - 2002 e 2006. Anais do 36 Encontro anual da ANPOCS. Aguas de Lindoia, 2012. Disponível em: <http://www.anpocs.com/index.php/papers-36-encontro/gt-2/gt25-2/8123padroes-geograficos-das-coligacoes-eleitorais-no-brasil-uma-analise-pela-perspectivaideologica-dos-partidos-politicos-2002-e-2006/file>. Acesso em: 07 jun. 2017. 